Original Article

\title{
Comparison of motor and process skills among children with different developmental disabilities
}

\author{
MYOUnG-OK PARK, OT, MPH ${ }^{1)}$ \\ 1) Department of Occupational Therapy, Division of Health Science, Baekseok University: Munam-ro \\ 76, Dongnam-gu, Cheonan-si, Chungcheongnam-do, Repubilc of Korea
}

\begin{abstract}
Purpose] The purpose of the present study was to compare the motor and process skills of children with different developmental disabilities. [Subjects] Thirty-nine children with developmental disabilities participated in this study which was conducted at N hospital in South Korea. [Methods] The motor and process skills of the participants were compared among three different disabilities: pervasive developmental disorder, cerebral palsy, and intellectual disorder. The data were analyzed using descriptive statistics and one-way ANOVA. [Results] Significant differences in motor skills were found among the diagnoses. The cerebral palsy group showed poorer motor skills than the pervasive developmental disability and intellectual disability groups. [Conclusion] The findings have clinical implications for strategies of rehabilitation for children with developmental disabilities.

Key words: Developmental disability, Motor skill, Process skill
\end{abstract}

(This article was submitted Jun. 19, 2015, and was accepted Jul. 13, 2015)

\section{INTRODUCTION}

According to the American Psychiatric Association's Diagnostic and Statistical Manual of Mental Disorder-V, developmental disabilities include intellectual disability, learning disability, motor dysfunction, communication disorders, pervasive developmental disorders, and attention deficit and hyperactivity disorder ${ }^{1}$. In general, children with developmental disabilities present various problems, such as gross and fine motor, somatosensory, cognition, language, and behavioral disorders ${ }^{2,3)}$. Children with developmental disabilities have difficulty performing functional activities due to these problems ${ }^{4}$. According to Occupational Therapy Practice Framework-III, in order to perform purposeful activities in daily life, we need motor, process, and socialinteraction skills. Motor skills are goal-directed actions that a person enacts when interacting with and moving task objects and themselves around task environments ${ }^{5}$. Process skills are related to the goal-directed actions that a person enacts when selecting, interacting with, and using task tools and materials, carrying out individual task actions and steps, and modifying task performance when problems are encountered $^{6}$. Children with developmental disabilities have motor and process skill deficits because they have difficulty with physical, mental, and intellectual functions ${ }^{7)}$. These problems are expected to present diverse patterns of motor and

Corresponding author. Myoung-Ok Park (E-mail: parkmo@ bu.ac.kr)

(C)2015 The Society of Physical Therapy Science. Published by IPEC Inc. This is an open-access article distributed under the terms of the Creative Commons Attribution Non-Commercial No Derivatives (by-ncnd) License $<$ http://creativecommons.org/licenses/by-nc-nd/3.0/>. process skills across diagnose, and these are important issues for rehabilitation intervention. Therefore, the purpose of this study was to compare differences in motor and process skills across the diagnoses of developmental disabilities.

\section{SUBJECTS AND METHODS}

The design was a cross-sectional study comparing motor and process skills measured by the Assessment of Motor and Process Skills, AMPS. The participants were 39 children with developmental disabilities attending $\mathrm{N}$ hospital in Seoul, 25 males (64.1\%) and 14 females (35.9\%) with a mean age of 7.5 years $(\mathrm{SD}=2.6)$. All participants received an explanation about the purpose and methods of the study in accordance with the ethical principles of the Declaration of Helsinki prior to their participation, and this study was approved by the institutional review board of Korea University (KU-IRB-11-09-P-1). The inclusion criteria were children who were between three and twelve years old who were receiving a developmental disability diagnosis who had a possible assessment of motor and process skills. AMPS was used to measure motor and process skills while performing daily living activities. AMPS was developed by Fisher to measure occupational performance in daily life. AMPS consists of two evaluation areas: motor skills and process skills. Motor skills are related to physical interactions between tasks and the environment when an individual performs activities, and are composed of various sub-items, such as body alignment, stabilization, and manipulation ${ }^{8}$. Process skills have relevance to using, interacting with, and choosing tools for tasks and correction when a person identifies problems in performing tasks, and process skills have various sub-items, including attention skills, and heeds ${ }^{9}$. All participants were assessed by an occupational therapist who 
Table 1. Motor and process skills with significant differences among the diagnose (logit)

\begin{tabular}{|c|c|c|c|c|c|}
\hline \multirow{2}{*}{ Diagnosis } & \multirow{2}{*}{$\mathrm{N}$} & \multicolumn{2}{|c|}{ Motor skill* } & \multicolumn{2}{|c|}{ Process skill } \\
\hline & & Mean (SD) & $F(d f)$ & Mean (SD) & $F(d f)$ \\
\hline PDD & 13 & $1.46(0.80)$ & & $0.13(0.66)$ & \\
\hline $\mathrm{CP}$ & 12 & $0.15(0.69)$ & $7.88(2,36)$ & $-0.13(1.09)$ & $0.32(2,36)$ \\
\hline ID & 14 & $1.34(1.13)$ & & $0.02(0.73)$ & \\
\hline
\end{tabular}

$* \mathrm{p}<0.05$

PDD: pervasive developmental disorder; CP: cerebral palsy; ID: intellectual disability

had previously been trained in the administration and scoring of AMPS. Descriptive statistics were used for demographic characteristics, and one-way ANOVA was used to analyze the data and groups of diagnosis. SPSS software (ver. 20.0. Chicago, USA) was used to perform statistical analysis, and the statistical significance level was chosen as 0.05 .

\section{RESULTS}

The area of motor skills showed significant differences with diagnosis; however, the difference in process skills were not significant (Table 1). The results of the Bonferroni post-hoc test indicate that the cerebral palsy group had a lower mean motor skills' score than the pervasive developmental disability and intellectual disability groups. The mean difference in motor skills between the pervasive developmental disability and intellectual disability groups was not significant (Table 2).

\section{DISCUSSION}

According to the results of this study, the area of motor skills showed significant differences among the pervasive developmental disability, cerebral palsy, and intellectual disability groups. Additionally, the results of the post-hoc test indicate the cerebral palsy group had lower motor skills than in the pervasive developmental disability and intellectual disability groups. Similarly, Kottorp et al. reported motor skills showed significant differences among children with cerebral palsy, intellectual disabilities, and autism ${ }^{5}$. This is because motor skills are related to gross and fine motor functions, including postural control, muscle tone, body alignment, and movement coordination. Moreover, children with cerebral palsy have specific characteristics related to motor functions, such as abnormal postural tone and movement patterns due to damage in the cerebral cortex, compared to other groups. However, children with cerebral palsy, pervasive developmental disorders, and intellectual disabilities showed similar process skills. As with all studies, the present study had limitations. The number of children was small, and further studies should recruit greater numbers of participants. Nevertheless, the result of this study have clinical implications for rehabilitation intervention, because this study found differences in motor and process skills among children with different developmental disabilities when they performed daily living activities.
Table 2. Result of the Bonferroni post-hoc test for motor skill (logit)

\begin{tabular}{cccc}
\hline $\begin{array}{c}\text { Diagnosis } \\
(\mathrm{I})\end{array}$ & $\begin{array}{c}\text { Diagnosis } \\
(\mathrm{J})\end{array}$ & $\begin{array}{c}\text { Mean difference } \\
(\mathrm{I}-\mathrm{J})\end{array}$ & Standard error \\
\hline \multirow{2}{*}{ PDD } & CP & $1.31^{*}$ & 0.36 \\
& ID & 0.12 & 0.35 \\
CP & PDD & $-1.31^{*}$ & 0.36 \\
& ID & $-1.19^{*}$ & 0.35 \\
ID & PDD & -0.12 & 0.35 \\
& CP & $1.19^{*}$ & 0.35 \\
\hline
\end{tabular}

$* \mathrm{p}<0.05$

PDD: pervasive developmental disorder; CP: cerebral palsy; ID: intellectual disability

\section{ACKNOWLEDGEMENT}

This research was supported by the Baekseok University.

\section{REFERENCES}

1) Diagnostic and Statistical Manual of Mental Disorders, 5th ed. American Psychiatric Association, 2013.

2) Humphry R: Young children's occupations: explicating the dynamics of developmental processes. Am J Occup Ther, 2002, 56: 171-179. [Medline] [CrossRef]

3) Song CS: Relationships between physical and cognitive functioning and activities of daily living in children with cerebral palsy. J Phys Ther Sci, 2013, 25: 619-622. [Medline] [CrossRef]

4) Gantschnig BE, Fisher AG, Page J, et al.: Differences in activities of daily living (ADL) abilities of children across world regions: a validity study of the assessment of motor and process skills. Child Care Health Dev, 2015, 41: 230-238. [Medline] [CrossRef]

5) Occupational therapy practice framework: domain and process, 3rd ed. Am J Occup Ther, 2013, 68: S1-S48.

6) Kottorp A, Bernspang B, Fisher AG: Activities of daily living in persons with intellectual disability: strengths and limitations in specific motor and process skills. Aust Occup Ther J, 2003, 50: 195-204. [CrossRef]

7) Kottorp A, Bernspång B, Fisher AG: Validity of a performance assessment of activities of daily living for people with developmental disabilities. J Intellect Disabil Res, 2003, 47: 597-605. [Medline] [CrossRef]

8) Girard C, Fisher AG, Short MA, et al.: Occupational performance differences between psychiatric groups. Scand J Occup Ther, 1999, 6: 119-126. [CrossRef]

9) Peny-Dahlstrand M, Gosman-Hedström G, Krumlinde-Sundholm L: Are there cross-cultural differences of ADL ability in children measured with the Assessment of Motor and Process Skills (AMPS)? Scand J Occup Ther, 2012, 19: 26-32. [Medline] [CrossRef] 